This item was submitted to Loughborough's Research Repository by the author.

Items in Figshare are protected by copyright, with all rights reserved, unless otherwise indicated.

\title{
What does the world spend on policing?
}

PLEASE CITE THE PUBLISHED VERSION

PUBLISHER

(c) Sage

LICENCE

CC BY-NC-ND 4.0

\section{REPOSITORY RECORD}

Farrell, Graham, Erin Lane, Ken Clark, and Andromachi Tseloni. 2019. "What Does the World Spend on Policing?". figshare. https://hdl.handle.net/2134/641. 
This item was submitted to Loughborough's Institutional Repository by the author and is made available under the following Creative Commons Licence conditions.

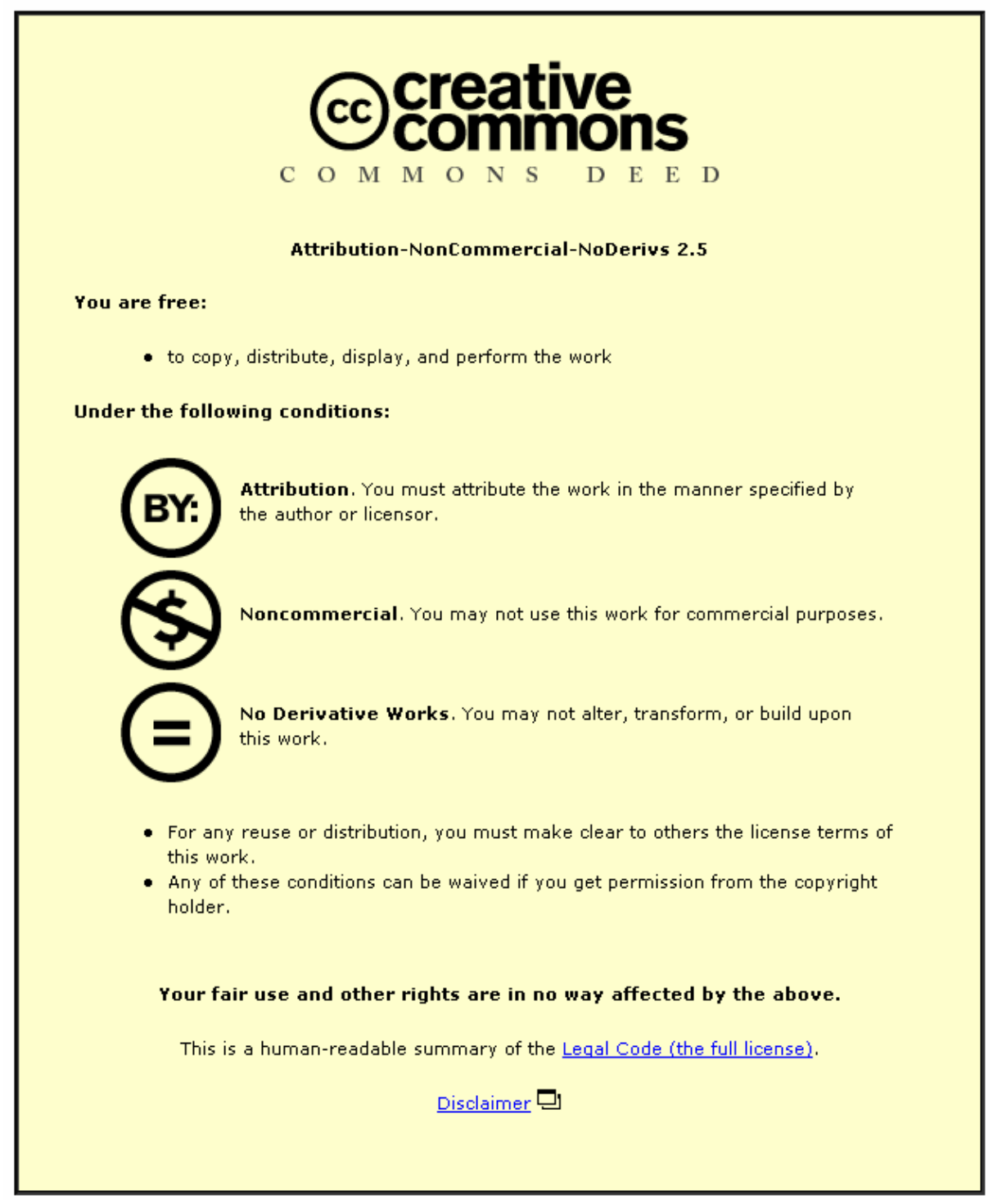

For the full text of this licence, please go to: http://creativecommons.org/licenses/by-nc-nd/2.5/ 


\title{
What Does the World Spend on Policing?*
}

\author{
GRAHAM FARRELL, ERIN LANE, KEN CLARK, \\ and ANDROMACHI TSELONI
}

\begin{abstract}
Social indicators vary in their breadth and coverage. One popular indicator of the priority that society gives to specific areas of life is a measure of monetary expenditure. Do we spend more or less on $\mathrm{X}$ or on $\mathrm{Y}$ ? Is the balance correct? A necessary precursor to such comparisons is measurement. This paper presents a method for estimating annual global expenditure on policing. Data from the fifth sweep of the United Nations Survey of Crime Trends and Criminal Justice Systems are supplemented with information from other sources. The relationship between gross domestic product and policing expenditure is examined via regression methods. The coefficients are used to extrapolate across space to produce national policing estimates from which a global estimate is derived. It is estimated that the world spent U.S. $\$ 194$ billion on public policing in the year 2000. The method utilized to produce this estimate is described, and the implications and possibilities for future research are discussed.
\end{abstract}

\section{Introduction}

$\mathrm{P}$ UBLIC EXPENDITURE is always a concern for taxpayers and policy makers alike. Everyone wants value for money, effective and efficient resource allocation, and to spend public monies most appropriately. Yet knowing how much is spent is a prerequisite for making such judgments. This is no less true for policing than for other areas of public policy. At the local level, police chiefs examine expenditures on the various units and sections operating within their jurisdiction. At regional levels, such as provinces in Canada, counties in the U.K., and states in Australia, India, and the United States (Bayley 1992 compares police organizations in these countries), police managers look at overall expenditures and try to determine whether the monetary grease is getting to the crime squeak.

- Direct correspondence to Graham Farrell. The Police Foundation. 1201 Connecticut Avenue NW, Washington DC. 20036. USA. The authors are indebted to Ken Pease. Professor of Criminology at the University of Huddersfield, for comments on an earlier draft and to Matthew Fleming of the International Monetary Fund for assistance in obtaining the relevant currency exchange rates. 
At the national level, policy makers may look at policing expenditures between regions or states and try to match them according to some sort of criteria such as expenditure per capita or per crime. This is all part of the public policy process of determining the balance between equity and efficiency in resource allocation. At the international and global level, statistics are now frequently used to compare countries and to develop global figures from which we can judge how well individual countries are doing, as well as how we are doing as a planet.

While national estimates allow cross-country comparisons, global estimates allow across-issue comparisons. As a planet, do we spend more on policing or on health? Do we spend more on policing or education? What is the disparity between them? If such disparity exists, is it appropriate in terms of addressing global priorities? Comparisons outside the realm of public expenditure also serve as social indicators of a different sort: Do we spend more on policing than on burgers and fries? (see Figure 1); fish and chips?; wine and beer?; oil and petroleum? Comparisons of such seemingly disparate commodities are of sociological interest, since they give some indication of society's priorities and preferences. As such, changes in those priorities over time can also be monitored. If, for example, more or less is spent on policing over time - in relative as well as absolute terms when compared to other indicators - then this might arguably be said to reflect changes in society's priorities.

It is in this context that the present paper reports what the authors' believe to be the first estimate of global expenditure upon policing. The primary data source is the fifth sweep of the United Nations Survey of Crime Trends and Criminal Justice Systems (UNCJS), the most recent version of the survey in the public domain at the time of writing. Based on national-level estimates of policing expenditure for all countries reporting that data item, an estimate is made of how much is spent globally on policing in the year 2000. It is presented as a first effort with acknowledged limitations. As such, if it serves to provoke the production of a more

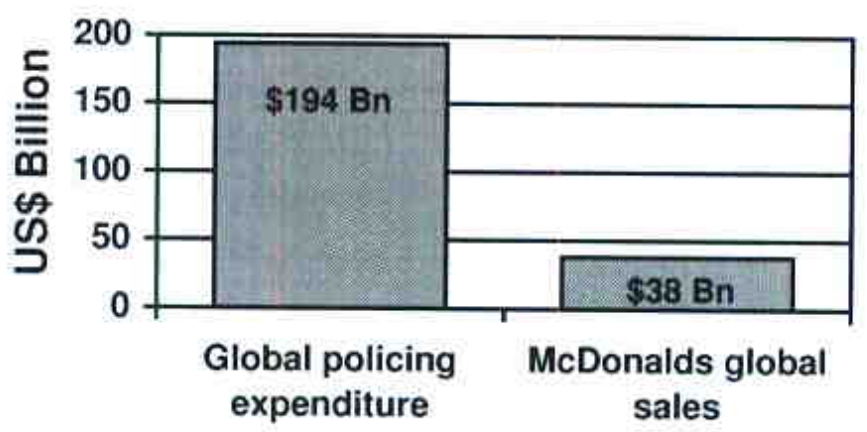

Figure 1. Global Social Indicators, 1999-2000. Sources: Fifth UNCJS and McDonalds (2000). 
refined estimate, as well as improvements in the collection and collation of the relevant information, then the task of the present study will have been served.

\section{Calculating Global Policing Expenditure}

The method of calculating global policing expenditure is conceptually simple. The UNCJS provides data relating to expenditure on policing for some, but not most, countries. As Newman and Howard (1999b:140) demonstrated, there is a strong and positive relationship between per capita expenditure on policing and per capita gross domestic product (GDP). Hence, for countries where the information on policing expenditure is not known, an estimate can be derived based upon knowledge of per capita GDP since the relationship between GDP and policing expenditure is known. From there, it is a short step to an estimate of global policing expenditure. As always, the practice was slightly more complex than the concept. The specifics of the method are explained in more detail after an introduction to the dataset.

\section{The One-eyed Database}

There is an old and gender-biased adage that, in the land of the blind, the oneeyed man is king. Thus it is with the UNCIS database for significant aspects of comparative criminology. While the data have a range of acknowledged limitations, the alternative is usually worse, if it exists at all.

The present study utilized the fifth sweep of the UNCIS survey. The survey has its origins in the 1970s, was undertaken every five years for the first five sweeps, and has changed in orientation over time (see Burnham 1999 for an overview of the history of the survey). Some countries do not respond to the survey while others only respond to parts of the survey. Further, it is sometimes difficult to compare the same data item across countries due to legal and definitional differences. These methodological issues have been reviewed and discussed at length elsewhere in relation to different aspects of the survey (see e.g. Joutsen 1998; Newman 1999; Van Horne and Farrell 1999). It is despite such limitations that the survey provides what is, at the time of writing, probably the best global information relating to many areas of criminal justice. The survey has been the primary data source for a number of studies over the years, including those by Nalla and Newman (1994), Harvey et al. (1992), Pease (1994), Tseloni and Pease (1994), and Kangaspunta et al. (1998a, 1998b). Jon Spencer (1993) recognized the utility of measuring global expenditure on criminal justice, and a series of studies brought together in a recent publication under the auspices of the United Nations Centre for International Crime Prevention may have proven the utility of the survey to even the most skeptical of its critics (Newman and Howard 1999a, b; Lewis 1999; Mukherjee and Reichel 
1999: Shinkai and Zvekic 1999). The UNC.IS survey has facilitated unprecedented insights into various aspects of the global criminal justice system. Newman and Howard (1999a) made a most insightful statement addressing the issue of the reliability and accuracy of the survey data when they noted:

There are many difficulties for researchers and policy makers alike in using and interpreting the UNCIS statistics. These statistics are, first and foremost, official statistics of member countries. They are, in fact, probably the most official statistics of international crime and justice that are published anywhere. One only need observe the ways in which countries behave internationally as entities - the ritual care with which they make statements in the international arena - to realize that a country's open announcement of the extent of its crime problem and its processing of offenders through the criminal justice system is a major political event. Countries do not reveal such information to other countries (and often to their own citizens) unless this information has been rigorously checked, not only for its 'validity' but also for the impression that it creates (p. 8, emphasis added).

Some of the methodological issues relating to cross-national comparisons of policing and the U.N. survey are worth covering in more detail. In his analysis of criminal justice expenditure using UNCJS data from the 1980s and performing analysis different from that herein. Jon Spencer (1993) observed:

$[\mathrm{O}]$ ne country may spend more on the police than another but may not have any more police - it is just that they pay them more. However, this type of distinction is difficult to make due to definitional problems of who the police actually are; in some countries the police are included as part of the military. Are special, voluntary or part-time police officers included? (pp. 10-11, fn 1.)

Ineke Haen Marshall provides an excellent overview of the policing resource aspects of the present UNCJS database:

The Fifth United Nations survey instrument defines the police or law enforcement sector as any ' $[\mathrm{P} \mid$ ublic agencies whose principal functions are the prevention, detection and investigation of crime and the apprehension of alleged offenders' (page 10). In some countries, these functions are performed by para-military or military forces or national security forces. For this reason, the administrator responsible for completing the U.N. questionnaire is asked to $\ldots$.. try to limit as far as possible replies to the civil police proper as distinct from national guards or local militia (p. 10)' (Marshall 1998:57).

Marshall's discussion was focused upon the measurement of personnel resources. Since these typically constitute a large part of police expenditure, the issues are relevant to the present study. Marshall (1998) groups the definitional issues relevant to measurement into two main categories: 
First, the distinction between sworn/uniform and civilian police is problematic. Civilian police personnel is increasingly important as police officers now are aided by a far larger number of civilian employees in the police service than in the past... However, what exactly is civilian police personnel? Does it include support staff. such as secretaries, computer specialists, and crime lab technicians? Some countries (such as Moldova) indicate that they have no civilian police personnel (leaving it open to speculation whether this means in contrast to military, or in contrast to uniformed personnel), while others (such as Liechtenstein and Northern Ireland) simply leave this part of the question blank. Second, even when focusing on 'total police,' some of the national figures provided in the responses may be questionable, reflecting the impossibility of summarizing often very complex systems of policing (centralized or decentralized, with different structures and organizations, under different jurisdictions) into one single summary measure (p. 57).

These authors capture many of the significant methodological issues relating to the present dataset and study. Another potential source of variation may be countries with secret police forces that may not include those elements of the police in their estimates of expenditure, or may not fully disclose information to the survey. In other instances, items included in the estimate of expenditure upon policing may vary, so that a budget item falling under policing in one location may fall under a different category in another. The present research study is therefore offered as a preliminary effort to produce an estimate of global policing expenditure while at the same time acknowledging that such variations may influence the direct comparability of country-level estimates. However, if the present sample is representative, then this would significantly reduce such concerns. This issue is considered later.

\section{Method}

If all of the world's countries responded accurately to all items in the UNCJS questionnaire, the present study would only have taken minutes to complete: national policing expenditure could be summed across countries. However, since the dataset is incomplete. the bulk of the present study is concerned with trying to fill gaps in the data. Two main techniques constituted this process. The first was to supplement the UNCJS data with country-level information from other sources. This was undertaken for the variables relating to currency exchange rates, population, and GDP. The second step was to extrapolate from countries for which data were available to countries for which they were not. Implicit to the method is the argument that the assumptions made are hopefully the least worst under the circumstances. and that without them a global estimate of policing expenditure would not be possible. In what follows, the currency referred to is U.S. dollars. 
It is acknowledged that the policing expenditure estimates produced herein will undoubtedly contain errors in estimates for individual countries. Some estimates will be higher and some will be lower than the true figures. It is not unreasonable to expect that in the aggregate, since no particular bias toward higher or lower is anticipated, such errors may largely balance out. In addition, since many of the countries for which data were absent were countries with relatively smaller GDPs, they would make less of an overall contribution to the global expenditure estimate. Therefore, the impact of an error factor would be proportionally less. This is touched on further in what follows.

\section{Supplementing the UNCJS Data}

The most recent year for which UNCJS data were available was 1994. The UNCJS data were supplemented with information from other sources with respect to three variables. These were the currency exchange rates between national currencies and U.S. dollars, national population estimates, and national GDP estimates. Population estimates were readily available from information provided with a popular spreadsheet program. Some currency exchange rate information was available in the UNCJS database, and this was supplemented with information provided by our colleague Matthew Fleming from the database of the International Monetary Fund.

Information relating to GDP was taken from the Human Development Report of the United Nations Development Program (UNDP 1998). This provided information for 94 percent of countries. For those countries for which the UNDP report did not provide the relevant figure, the per capita GDP for countries in the same U.N. income aggregate group was used as the substitute. For countries that were not categorized into a U.N. income-aggregate group, the mean of countries in that U.N. geographical region was utilized. While this may produce only ballpark estimates of GDP, ten of the twelve countries for which the method was used had populations of less than 100,000 people, and one had less than half a million citizens. The largest absentee was the country then known as Yugoslavia, with a population of ten million. Despite the presence of one medium-sized country, any error factor incurred in relation to these countries should have a negligible impact upon the overall estimate of global policing expenditure.

The fifth UNCIS asked countries how much money they spent on policing for 1990 and 1994. The United States was the only country that reported policing expenditure for 1990 but not 1994 . The 1990 figure of $\$ 35.9$ billion for the U.S. was adjusted for inflation to create a figure for 1994 of $\$ 40.6$ billion. $^{1}$ 


\section{The Relationship between GDP and Expenditure on Policing}

For the thirty-five countries for which annual policing expenditure estimates were provided to UNCJS, local currency estimates were converted to U.S. dollar estimates to make them comparable. These were then converted to per capita rates to allow comparison using a common denominator. Such a comparison had been previously undertaken by Newman and Howard (1999b:140). However, their analysis had only 22 data points. In the present study, supplementing the data with information from other sources increased the useable sample size by 60 percent to thirty-five countries.

That a strong positive relationship between per capita GDP and per capita policing expenditure emerged in Figure 2 is not particularly surprising. Rich countries can spend more per capita upon policing because they have larger public policy purses based on taxation from higher incomes.

The next steps of the study aimed to extrapolate from these data to the remaining countries. This involved producing national estimates of policing expenditure from which a global estimate could be produced. As the work progressed, it became evident that there were different ways of calculating such an estimate, and three sets of estimates were produced from econometric models with different specifications. Each is described in turn below.

\section{Model 1: Per Capita Model}

The Pearson's correlation coefficient showed a highly significant $(n=35$, $r=0.662, p<0.001$ ) positive relationship between GDP per capita and policing expenditure per capita. It is also evident from Figure 2 that there is a clear

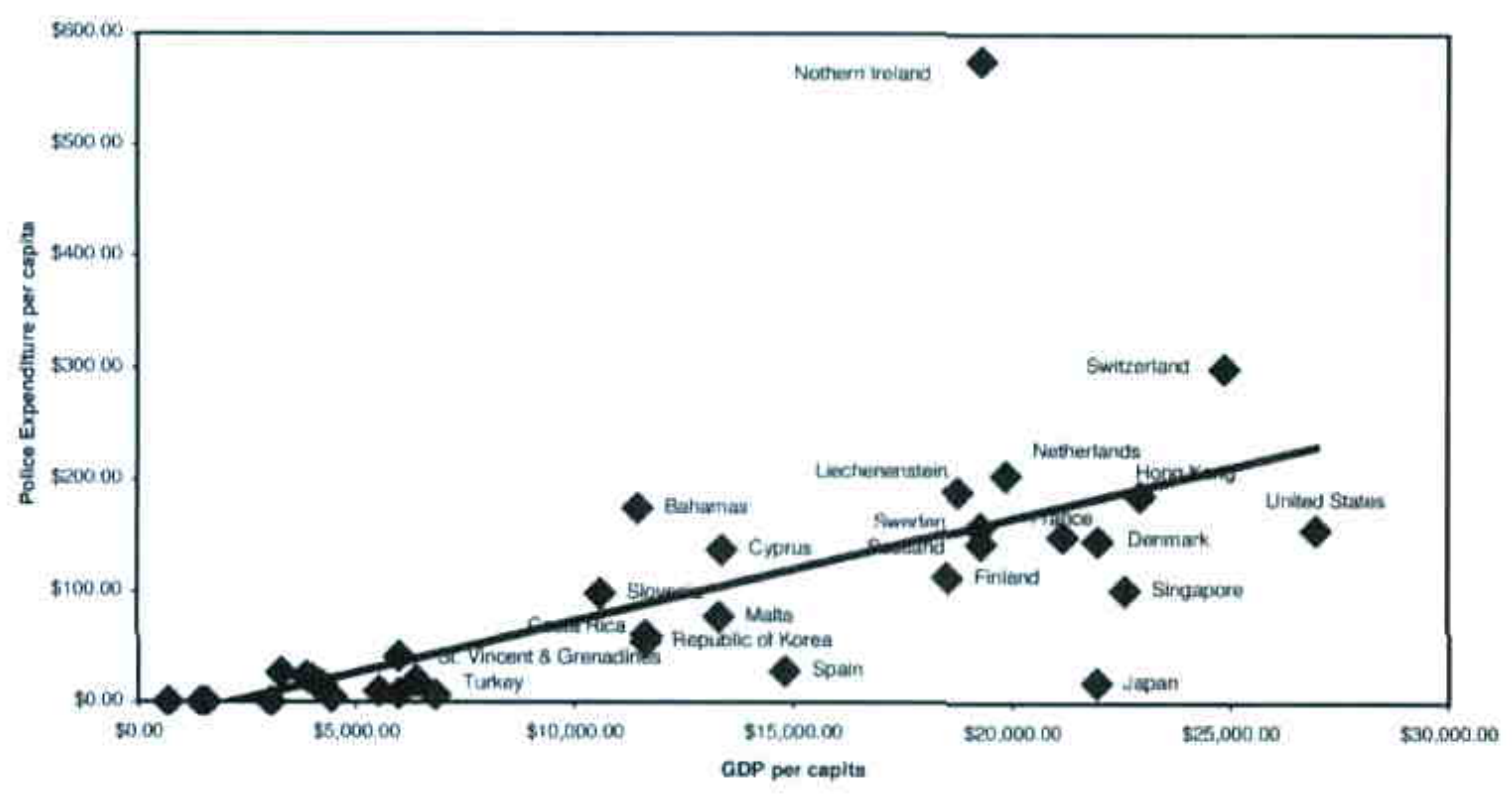

Figure 2. Police Expenditure and GDP Per Capita, 1994. 
outlier, Northern Ireland, with per capita police expenditure far above the bestfit regression line, which has been superimposed on the Figure. Throughout the analysis, Northern Ireland is treated as a special case by the inclusion of a dummy variable that takes the value one for Northern Ireland and zero otherwise.

An ordinary least squares regression of per capita policing on per capita GDP produced the fitted equation:

$$
\begin{aligned}
P / K= & 0.006977 G / K+440.8801 n i \\
& (0.0006)
\end{aligned}
$$

where $P$ is policing expenditure in a country in 1994 dollars, $G$ is GDP in millions of dollars, $K$ is the country population in millions, and $n i$ is the dummy variable for Northern Ireland. Note that the constant was suppressed from the regression as a statistical test suggested that it was insignificantly different from zero. Throughout this text, standard errors of the coefficients are shown below and in parentheses. This model suggests that out of every dollar of per capita GDP, the world spent around .7 cents per person on policing in 1994.

Using this method of estimation to predict per capita policing for each of the 199 countries, the median per capita expenditure on policing per country was $\$ 28$ and the mean was $\$ 52$. In this instance the mean is less representative than the median due to the skewed distribution of per capita GDP. The per capita policing expenditure was multiplied by country population to give an overall policing expenditure estimate for each country. The sum of these gave a first global policing expenditure estimate of \$228 billion for 1994. Applying the dollar inflation rate provided by the U.S. Bureau of Labor Statistics, yielded an estimate for the year 2000 of \$U.S. 264 billion.

\section{Model 2: Linear Multiple Regression Model}

The model described above could be considered restrictive for two reasons. First, it imposes an exact relationship between per capita values that restricts interaction between the variables in a manner that may be implausible. Second, the model imposes a purely linear structure on the data that may not reflect the underlying relationship between the variables.

To see the potential drawbacks associated with the first of these issues, consider what the estimated model implies about a situation in which the population in a country changes. For the sake of illustration, suppose that the population doubled. Then GDP per capita would fall by half and, likewise, per capita policing expenditure would also fall to half its previous level. However, this model imposes the restriction that total police expenditure is invariant to population growth. In practice, conditional on a given level of GDP, more or less populous countries policing expenditure might vary. The proposed modification to the regression model is to estimate a multiple regression of total policing expenditure in which 
population and total GDP enter as separate independent variables. This allows population growth to affect total policing expenditure independently of its impact on per capita GDP.

Using the same notation, the linear multiple regression model was estimated as

$$
\begin{array}{r}
P=-7.98 K+0.0055 G \\
(2.636) \quad(0.0003)
\end{array}
$$

This produced a global policing expenditure estimate of $\$ 136.5$ billion for 1994 . or, adjusted for inflation, $\$ 158.3$ billion for 2000 .

\section{Model 3: Double Log Multiple Regression Model}

To account for the influence of nonlinearity in the relationship, a logarithmic version of the multiple regression model was estimated. The statistical test of Box and Cox (1964) was applied to establish whether the logarithmic version of the model fit the data better than its linear counterpart. The results of this test (available on request) strongly indicated that the logarithmic model was preferred. The Northern Ireland dummy variable was dropped since the coefficient was not significantly different from zero and it made the estimators less efficient. The estimated model was:

$$
\begin{aligned}
\log (P)= & -1.52 \log (K)+2.233 \log (G)-16.51 \\
& (0.2648)
\end{aligned}
$$

where $\log (P)$ is the logarithmically transformed level of total policing expenditure for a country in 1994 U.S. dollars, $\log (G)$ is the country's logarithmically transformed GDP, and $\log (K)$ is its total population also logarithmically transformed. This equation was used to predict $\log (P)$ for each of the countries in the sample and then this figure was converted back into dollar units to obtain the estimates of each country's total policing expenditure.

Applying this more flexible statistical technique yielded an estimate of global policing expenditure of $\$ 95.7$ billion in 1994 dollars. When the predicted values were replaced with the true values for the thirty-five countries for which they were available, a 1994 estimate of $\$ 106.3$ billion was produced. Adjusted for inflation this produced an estimate for 2000 of $\$ 123.3$ billion. This is the estimate from Model 3 without the application of a correction for bias, detailed below.

A correction for bias was subsequently applied to Model 3 . The bias correction refers to retrieving the dollar values from the predicted values of the double log model. The predicted values are in log units and it would be natural to take the antilog to get the dollar value back. This approach is advocated by a number of forecasting textbooks (e.g., Wood and Fildes 1976). However, Granger and 
Newbold (1977) argue that this is statistically incorrect. Specifically, they show that the mean of the error term in the logarithmic model is non-zero which implies that the antilogged predicted value from (3) is a biased estimator of the true underlying value of policing expenditure. The bias correction is intended to compensate for this. In other contexts it has been suggested (Harvey 1990, for example) that this correction will make little difference to the estimates, although this turns out not to be the case in the present application. Applying the bias correction increases the estimate of global policing expenditure for 1994 to $\$ 167.1$ billion, producing an inflation-adjusted estimate of $\$ 193.8$ billion for the year 2000 .

\section{Is the Sample Representative?}

A key issue remaining is whether or not the sample of thirty-five countries was representative of the world as a whole. If the sample of countries were representative, then many of the potential methodological issues relating to definitional differences in policing between countries would arguably be significantly reduced. Without representativeness, extrapolation from thirty-five countries to one hundred and ninety-nine seems likely to produce a skew in the findings. In fact, the key issue is whether the distribution of incomes in the sample will produce a predictor that is representative of the global pattern. Since there is a good spread across the overall range of global incomes, including a range of countries at the lower end as well as a number at the upper end (refer to Figure 1), there is no reason to believe that the predictions derived will be inaccurate. If anything, the more wealthy countries are overrepresented because they tend to have more established infrastructures with which to collate and report the relevant statistical information to the United Nations. This should be a good thing since it would be at the upper end of the income distribution that a greater variation in policing expenditure, relative to GDP, would be expected in absolute terms. In relation to the specific instance of estimating global policing expenditure, therefore, it is proposed that while the sample is possibly not representative of countries in the world, it is likely to embody a representativeness that is sufficiently accurate for the present exercise.

\section{Discussion and Suggestions for Further Research}

Three models were presented from which estimates of global policing expenditure were derived. The predictions change significantly depending on the model (Table 1). This is probably inevitable in an exercise that imputes values for 164 countries based solely on data on two explanatory variables in 35 countries. It is asking a lot of a very small sample of data representing countries which will exhibit a great deal of heterogeneity.

Which model is best? As discussed above, the per capita model (Model 1) imposes an implausible restriction on how the level of population can affect 
Table I

Global Policing Expenditure Estimates for the Models (US\$ Billions)

\begin{tabular}{lcc}
\hline Model & 1994 (\$ Billions) & 2000 (\$ Billions, inflation adjusted) \\
\hline Model 1 & 228.4 & 264.9 \\
Model 2 & 136.5 & 158.3 \\
Model 3 (uncorrected) & 106.3 & 123.3 \\
Model 3 (corrected) & 167.1 & 193.8 \\
\hline
\end{tabular}

policing expenditure; the multiple regression models allow for more flexibility in this relationship and may be preferred for that reason. As for the choice between Models 2 and 3, the test of Box and Cox unambiguously prefers Model 3, the double log specification. Moreover, of the other simple log transforms that could be undertaken, the double log dominates on the basis of simple goodness of fit statistics. Hence Model 3 has something to commend it and, given the arguments in favor of the bias correction, our "preferred" estimate for 1994 is $\$ 167.1$ billion, adjusted to $\$ 193.8$ for the year 2000 . Having said this, the range of estimates is quite wide and the reader should be aware of the sensitivity of the results to the statistical assumptions made.

It would be possible to estimate further variants of these models and subject them to a battery of statistical tests. In our view, due to the limitations of the data set, this would almost certainly result in rapidly diminishing returns. However, when subsequent sweeps of the UNCJS survey become available it may be possible to test the models developed here by repeating the exercise with new data for the same thirty-five countries in order to determine which model best predicts policing expenditure in the additional countries for which data are available.

This paper has presented a conceptually simple method for estimating global policing expenditure. The authors would be pleased if the present study stimulates a refinement of knowledge in this area. Future research may also examine changes in global policing expenditure over time. Comparisons of such change may give an indication of the relative importance of policing among the world's competing spending priorities.

The bulk of the present study was concerned with overcoming the problem of partial information. It reinforces the need for additional effort to be made to build upon and improve current data collection efforts relating to UNCJS. At the same time, it is hoped that the present study lends a little additional weight to the growing body of evidence that UNCJS can be utilized to a greater extent than it has been to date. The present method may be transferable to a range of areas of study. The UNCJS data analyzed here related to 1994, the most recent year available at the time of writing. The use of the inflation rate to derive an estimate for the year 
2000 is acknowledged to be questionable, for it makes the uncertain assumptions that per capita policing expenditures did not significantly change over six years. These may prove unreasonable assumptions. If the relevant data are collected for the year 2000 , the validity of the present estimates may be tested. With hindsight, it is possible that if policing expenditure data are available for earlier UNCJS sweeps, then the fifth survey might serve as a validity check for predictions based on data from prior years.

There are sobering variations between the different models presented. They reinforce the fact that the estimates are sensitive to changes in model specifications and assumptions. It is possible that a more accurate model could be developed by incorporating more independent variables, such as the percent of GDP spent on public expenditure, to reduce disparity between actual and predicted values.

The comparison of the global policing expenditure of $\$ 194$ billion to McDonalds global sales for 1999 of $\$ 38$ billion (see Figure 1) received surprisingly favorable comments from colleagues reading earlier versions of this paper. The indicator seemed to be one with which people could relate and provided an immediately grasped comparative context. The first author wishes that McDonalds glowing sales figure were due to the growing popularity of that company's vegetarian products, but it probably is not. ${ }^{2}$ Other indicators will be available that are more probing in relation to society's overall priorities. The World Health Organization (WHO) produces statistics on public health expenditure by country that, with some assumptions, allow a tentative comparative indicator to be developed. The WHO concludes that, on average, 2.6 percent of GDP is public health expenditure. ${ }^{3}$ They also report per capita GDP for the world to be $\$ 4,123$ in 1995 and estimate the global population at $5,884,576,000$ (slightly less than 6 billion people). This would produce a ballpark estimate of global public health expenditure of $\$ 630.7$ billion. This is a crude aggregate utilizing data from different years. It is perhaps suggestive of the potential for furthering this exercise rather than a precise effort. If it is anywhere near correct, then it suggests that global expenditure on public health is slightly more than three times that on public policing.

Without significant retrospective data collection, which seems unlikely to prove feasible, it is unlikely that further national-level data relating to 1994 policing expenditures are likely to become available. Hence, significant changes in the estimates produced here are unlikely without improvements to the regression techniques. Precise policing expenditure information for several additional countries would be unlikely to vastly change the regression results for the present models; therefore, the derived estimates are probably reasonably stable. It is hoped that time will tell how accurate these estimates prove to be.

The UNCJS data contain expenditure information for other areas of the global criminal justice system. Perhaps similar exercises to the present one are possible, so that overall expenditure on the global criminal justice system can be 
estimated. This may allow comparison between countries and over time of the GDP-criminal justice expenditure trajectories for policing, prosecutions, courts and prisons, between countries and overtime. Are countries that are outliers in relation to one area of criminal justice also outliers in relation to other areas? Do particular countries or groups of countries have particular signatures relating to criminal justice expenditures? Do countries exhibit general deviations or deviations that are specific to a particular stage of the criminal justice system? Have the differences increased over time? Have they followed common or divergent trends? There may be a rich vein of comparative indicators to be developed and explored.

\section{NOTES}

I Throughout the text. inflation adjustments were made according to information from the U.S. Bureau of Labor Statistics. In this instance, the inflation calculator on its website at http://www.bls.gov./cpihome.htm stated that \$1 in 1994 was equivalent to $\$ 1.16$ in 2000.

2 Police aficionados in the United States might be excused for anticipating that global donut sales would be the principal culinary reference point.

3 See http:/www. who.int/whr/1999/en/indicators.htm for statistics from the World Health Report 1999.

\section{REFERENCES}

\section{BAYLEY. David}

1992 "Comparative Organization of the Police in English Speaking Countries." Pp. 509-46 in Modern Policing. edited by M. Tonry and N. Morris. Chicago: University of Chicago Press.

BURNHAM, R.W.

1999 "A Short History of the Collection of U.N. Crime and Justice Statistics at the International Level." P. 2 in Global Report on Crime and Justice, edited by G. Newman. New York: Oxford University Press.

Box. G.E.P. and D.R. COX

1964 "An Analysis of Transformations." Journal of the Royal Statistical Society Series B 26:211-243.

Granger, Clive, and Paul Newbold

1977 Forecasting Economic Time Series. New York: Academic Press.

HARVEY, Andrew

1992 The Econometric Analysis of Time Series. $2^{\text {nd }}$ Edition. Cambridge: MIT Press.

HARVEY. Linda. R.W. BURnham. Kathy Kendal.L., and Ken PEASE

1992 "Gender Differences in Criminal Justice." British Journal of Criminology 32:208-217.

JOUSTEN, Matti

1998 "Introduction." Pp. 1-19 in Crime and Criminal Justice Systems in Europe and North America 1990-1994, edited by K. Kangaspunta. M. Joutsen, and N. Ollus. Monsey, NY: Criminal Justice Press. 
KANGASPUnta, Kristina, Matti JoutSEn, and Natalia OLLus (Eds.)

1998a Crime and Criminal Justice Systems in Europe and North America 1990-1994. Monsey, NY: Criminal Justice Press.

1998b Profiles of Criminal Justice Systems in Europe and North America 1990-1994. Monsey, NY: Criminal Justice Press.

LEWIS. Chris

1999 "Police Records of Crime." Pp. 43-64 in Global Report on Crime and Justice, edited by G. Newman. New York: Oxford University Press.

MARSHALL, Ineke Haen

1998 "Operation of the Criminal Justice System." Pp. 54-114 in Crime and Criminal Justice Systems in Europe and North America 1990-1994, edited by K. Kangaspunta, M. Joutsen, and N. Ollus. Monsey, NY: Criminal Justice Press.

MCDONALDS

2000 "McDonalds Reports Record Global Results." McDonalds Financial Press Release 26 January 2000.

MukHerJeE, Satyanshu and Philip ReicheL

1999 "Bringing to Justice." Pp. 65-88 in Global Report on Crime and Justice, edited by G. Newman. New York: Oxford University Press.

NALLA, Mahesh K. and Graeme NEWMAN

1994 "Crime in the US and the Former USSR: A Comparison of Crime Trends from the Third United Nations Survey." International Journal of Comparative and Applied Criminal Justice 18:85-94.

NEWMAN. Graeme. Ed.

1999 Global Report on Crime and Justice. New York: Oxford University Press.

NEWMAN, Graeme and Gregory J. HOWARD

1999a "Introduction: Data Sources and their Use." Pp. 1-23 in Global Report on Crime and Justice, edited by G. Newman. New York: Oxford University Press.

1999b "Resources in Criminal Justice." Pp. 121-150 in Global Report on Crime and Justice. edited by G. Newman. New York: Oxford University Press.

PEASE, Ken

1994 "Cross-National Imprisonments Rates: Limitations of Method and Possible Conclusions." British Journal of Criminology 34:116-130.

PEASE, Ken and Andromachi TSELoni

1994 "Juvenile-Adult Differences in Criminal Justice: Evidence from the United Nations Crime Survey." Howard Journal of Criminal Justice 35:40-60.

SHINKAI, Hiroyuki and Ugljesa ZVEKIC

1999 "Punishment." Pp. 89-120 in Global Report on Crime and Justice, edited by G. Newman. New York: Oxford University Press.

SPENCER, Jon

1993 "Criminal Justice Expenditure: A Global Perspective." Howard Journal of Criminal Justice 32:1-11.

UNITED NATIONS DEVELOPMENT PROGRAM

1998 Human Development Report. New York: Oxford University Press. 
VAN HORNE. Sheryl and Graham FARRELL.

1999 "Drug Offenders in the Global Criminal Justice System" (HEUNI Paper No. 13). Helsinki: The European Institute for Crime Prevention and Control, affiliated with the United Nations.

WOOD. Doug and Robert FILDES

1976 Forecasting for Business: Methods and Applications. London: Longman. 


\section{LIST OF CONTRIBUTORS}

Cyndi Banks is Assistant Professor in the Criminal Justice Department at Northern Arizona University. She has conducted extensive research and fieldwork in Papua New Guinea during 13 years of residence. Her edited volume, Developing Cultural Criminology: Theory and Practice in Papua New Guinea, Sydney Institute of Criminology Monograph Series, Australia, addresses the issue of cultural specificity and the appropriateness of Western approaches to the study of crime in Papua New Guinea. She is currently working on a volume concerning the experience of Alaskan Native youth in a detention and treatment facility in Alaska. Her main research interests include: violence, comparative criminology, cultural specificity, indigenous experiences of the criminal justice system, and gender issues in developing countries.

Adam C. Bouloukos is the President of the Staff Council, United Nations Office at Vienna. Before being elected to that post in April 2000, he acted as a research officer in the United Nations Centre for International Crime Prevention. $\mathrm{He}$ holds an M.A. and Ph.D. in Criminal Justice from the University at Albany where he worked as co-editor of the Global Factbook of Criminal Justice Systems, and as an instructor. Dr. Bouloukos has co-authored two books and authored/co-authored several book chapters and articles on firearm regulation, repeat victimization, comparative criminal justice systems, and human rights.

Ken Clark is Senior Lecturer in the School of Economic Studies at the University of Manchester.

Ronald V. Clarke is University Professor at Rutgers, The State University of New Jersey. He has a long-standing interest in situational crime prevention and has published extensively in this field. He also edits the Crime Prevention Studies series, which pulls together significant research studies and theoretical papers on situational crime prevention.

Brett Dakin is a first-year student at Harvard Law School. Following his graduation from Princeton University with a Bachelor of Arts degree in East Asian Studies, he worked for two years as a tourism development consultant for the government of the Lao PDR in Vientiane, Laos, before completing an internship at the United Nations Office at Vienna. Mr. Dakin's research interests include promoting the rule of law in developing countries. 
Graham Farrell is Deputy Research Director at the Police Foundation in Washington DC. He earned a Ph.D. from the University of Manchester in 1994.

Joshua D. Freilich is Assistant Professor of Sociology at the John Jay College of Criminal Justice. He is completing a Ph.D. from the School of Criminal Justice at the State University of New York at Albany, where he also received a master's degree in 1996. He received a Juris Doctorate in 1993 from Brooklyn Law School and is admitted to the New York and New Jersey State Bars. His research interests include deviance and far-right social movements, and he has published manuscripts recently in Justice Quarterly and the American Journal of Criminal Justice.

Gregory J. Howard is Assistant Professor of Sociology at Western Michigan University. His current research and practice is concerned with social movements, resistance and revolt, environmental sociology, comparative criminology, and pedagogy.

Erin Lane is Research Associate at the Police Foundation in Washington DC, where she directs field research for the NIJ-supported project, RichmondPolice Foundation Domestic Violence Partnership, and for the COPS/Community Policing Test Site Project. She earned her master's in public management from School of Public Affairs at the University of Maryland in 1998. Prior to working at the Police Foundation she served as an intern with the United States Parole Commission.

Gloria Laycock is currently an International Visiting Fellow at the National Institute of Justice in Washington DC. She was formerly Head of the Police Research Group in the British Home Office. Her interests are in policing and crime prevention research and in increasing the use of evidence in policy and practice.

Edward R. Maguire is Associate Professor of Administration of Justice at George Mason University. Prior to that, he taught at the University of NebraskaOmaha and held research positions at the U.S. Department of Justice in Washington, DC, and the United Nations in Vienna, Austria. He received a Ph.D. in Criminal Justice from the State University of New York at Albany in 1997. His research focuses on police organization and innovation.

Mangai Natarajan (Ph.D.) is Associate Professor at the John Jay College of Criminal Justice of the City University of New York. She has been conducting comparative research on women policing for more than a decade and has published on the topic widely. She has acquired training in drug research through a National Institute of Drug Abuse postdoctoral fellowship and Scientist Development Award. 
Andromachi Tseloni is Assistant Professor in the Department of Criminology and Criminal Justice at the University of Maryland. She earned a Ph.D. from the University of Manchester in 1994 and is a member of the Committee on Justice Statistics of the American Statistical Society. 